\title{
Experimental Research on the Impact of Lubricating Oils on Engine Friction and Vehicle Fuel Economy
}

\author{
Yimin $\mathrm{Mo}^{\mathrm{a}}$, Junping Wang ${ }^{\mathrm{b}}$, Jun Wang ${ }^{\mathrm{c}}$, Tuo Dong ${ }^{\mathrm{d}}$ and Wenjun Zhou ${ }^{\mathrm{e}}$ \\ School of Mechanical and Electronic Engineering, Wuhan University of Technology, Wuhan, China \\ amoyimin@whut.edu.cn, bwangjpzm@163.com, ${ }^{\mathrm{c}} 15926481499 @ 163 . c o m,{ }^{d}$ whut_dt@163.com, \\ e332920622@qq.com.
}

Keywords: energy-conserving engine oil; low viscosity; friction modifier; viscosity index improver; engine friction; vehicle fuel economy

\begin{abstract}
The engine friction loss and vehicle fuel economy aiming at several kinds of energy-conserving engine oils with different quality standard, viscosity grade, friction modifier, and viscosity index improver were tested in this paper. Experimental results showed that the engine friction loss was reduced and vehicle fuel economy was improved by lowering the viscosity of engine oil and adding high-performance friction modifier and new-type viscosity index improver. Among which, the effect of energy-conserving engine oils Dexos $15 \mathrm{~W}-20$ adding $1 \%$ friction modifier and new type viscosity index improver was most significant with $12.45 \%$ engine friction reduction rate and $2.33 \%$ vehicle fuel economy improvement rate.
\end{abstract}

\section{Introduction}

With the continuous increase of car ownership in China, environment pollution and energy shortage are increasingly prominent, and automobile fuel consumption standards are increasingly strict as well, such as the average fuel economy standard of passenger car is $6.9 \mathrm{~L} / 100 \mathrm{~km}$ in 2015 and shall be down to $5.0 \mathrm{~L} / 100 \mathrm{~km}$ in 2020 . So the vehicle fuel economy improvement has become the focus for all countries in the world. Studies have shown that $60 \%$ of the energy of fuel combustion loses in cylinder cooling and exhaust emissions, $40 \%$ provides the effective power, but $25 \%$ of the effective power loses in the friction of engine parts [1]. Therefore, it is necessary to improve fuel economy by reducing engine friction loss. The ways to reduce engine friction loss are various, compared to the improvement of engine design and new materials processing technology, developing the energy-conserving engine oil is more practical and cost-saving.

Many studies have evaluated on the impact factors of engine oil fuel economy at home and abroad [2-3], but mostly lack of experimental verification. There are also many tests about the impact of lubricating oil viscosity and friction modifier on fuel economy [4], but the kind of test oil is limited and lack of vehicle test.

In this research, several kinds of energy-conserving engine oils were blended to evaluate the effect of viscosity, friction modifier and viscosity index improver on the fuel economy improvement of engine oil. And the engine friction torque and vehicle fuel consumption were tested to verify the improvement effects of these candidate oils.

\section{Test Oils}

Test Oils Blending. When normally running, the engine parts have different lubrication 
characteristics on account of the difference of temperature, load, and speed. Usually, the crankshaft and bearings are in hydrodynamic lubrication regime; friction between piston and liner is under mixed lubrication regime; and valve mechanism is a boundary lubrication regime [5]. According to different lubrication regimes, the approaches for energy-conserving lubricating oils to reduce engine friction are also quite different. The friction loss under hydrodynamic lubrication regime can be reduced with low viscosity engine oil. Besides, friction modifier (FM) can directionally adsorb on the metal surface through polar group, form a protective oil film preventing the direct contact of metals, so as to reduce the friction loss under the boundary lubrication regime [6]. In addition, the viscosity index of engine oils can be improved through adding a certain amount of viscosity index improver (VII), which makes the oils have better rheological properties and viscosity-temperature characteristic, thus to reduce friction and improve fuel economy. Six kinds of engine oils were blended aiming at the three aspects mentioned above. The formulations of the oils were specified in table 1.

Table 1 Formulation of the Test Oils

\begin{tabular}{ccccccc}
\hline Type & Reference & Candidate1 & Candidate(2) & Candidate (3) & Candidate(4) & Candidate (5) \\
\hline Standard & API SM & API SN & API SN & Dexos1 & Dexos1 & Dexos1 \\
Vis-grade & $5 \mathrm{~W}-30$ & $5 \mathrm{~W}-20$ & $0 \mathrm{~W}-20$ & $5 \mathrm{~W}-20$ & $5 \mathrm{~W}-20$ & $5 \mathrm{~W}-20$ \\
Base oil & III type & III type & III type & III type & III type & III type \\
Additives & $10 \sim 15 \%$ & $10 \sim 15 \%$ & $10 \sim 15 \%$ & $10 \sim 15 \%$ & $10 \sim 15 \%$ & $10 \sim 15 \%$ \\
FM & 0 & 0 & 0 & 0 & H.P*; $1 \%$ & H.P*; $1 \%$ \\
VII & $5 \sim 10 \%$ & $5 \sim 10 \%$ & $5 \sim 10 \%$ & $5 \sim 10 \%$ & $5 \sim 10 \%$ & N.T*; $5 \sim 10 \%$ \\
\hline
\end{tabular}

H.P*: High Performance; N.T*: New Type

Physical Indicator Test of the Engine Oils. According to relevant standards and rules, the physical indicators of engine oils were respectively tested. The results are shown in fig. 1 and table 2. Among the results, the viscosity index is calculated by the following equations:

$$
V I=[(L-U) /(L-H)] \times 100
$$

If the viscosity index of oils is greater than or equal to 100 , using the following equations:

$$
\begin{aligned}
& V I=[(\operatorname{anti} \log N)-1] / 0.00715+100 \\
& N=(\log H-\log U) \times \log Y
\end{aligned}
$$

Where $V I=$ viscosity index of test oils; $L=\mathrm{KV} 40$ of the oils whose KV100 is same to the test oil and the VI is $0 ; H=\mathrm{KV} 40$ of the oils whose KV100 is same to the test oil and the VI is 100 ; $U=\mathrm{KV} 40$ of test oils.
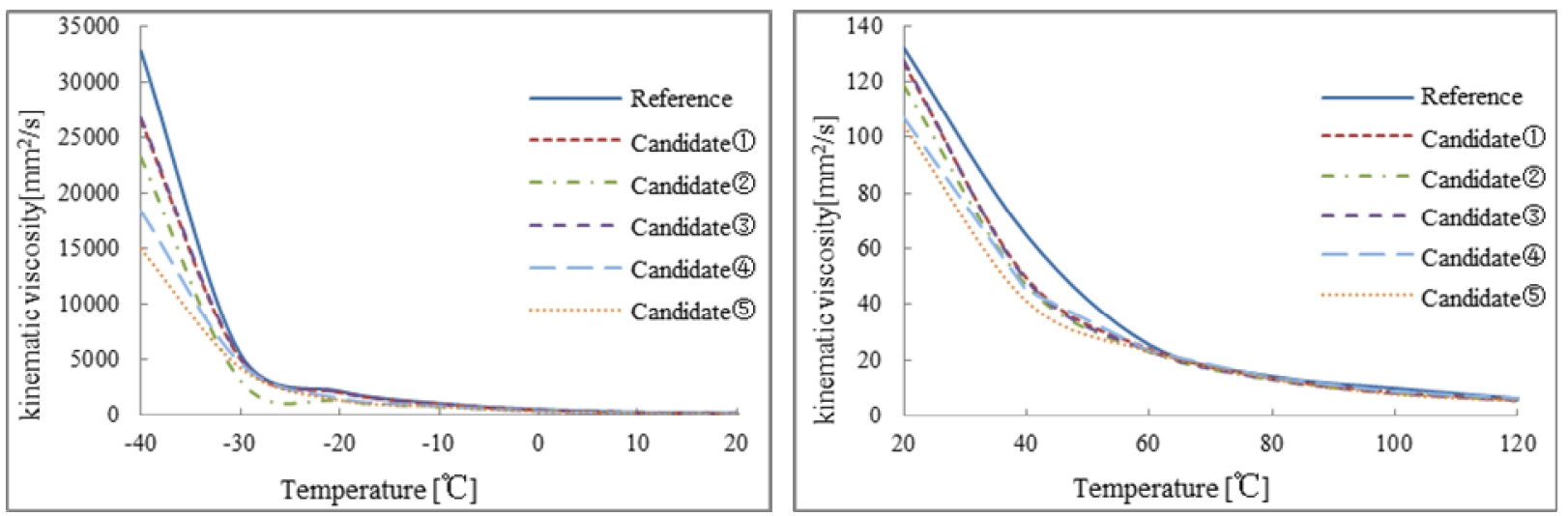

Fig. 1 Viscosity-Temperature Curve of the Test Oils at $\left(-40 \sim 20^{\circ} \mathrm{C}\right) \&\left(20 \sim 120^{\circ} \mathrm{C}\right)$ 
Table 2 Physical Indicator of the Test Oils

\begin{tabular}{ccccccc}
\hline Type & Reference & Candidate(1) & Candidate(2) & Candidate(3) & Candidate(4) & Candidate(5) \\
\hline $\mathrm{KV} 100\left[\mathrm{~mm}^{2} / \mathrm{s}\right]$ & 9.95 & 8.570 & 8.2 & 8.610 & 8.210 & 8.020 \\
$\mathrm{KV} 40\left[\mathrm{~mm}^{2} / \mathrm{s}\right]$ & 64.70 & 49.41 & 46.77 & 48.67 & 45.89 & 41.10 \\
$\mathrm{CCS}[\mathrm{mPa} \mathrm{s}]$ & 5460 & 5200 & 3100 & 5280 & 4660 & 4220 \\
$\mathrm{HTHS}[\mathrm{mPa} . \mathrm{s}]$ & 3.12 & 2.71 & 2.57 & 2.72 & 2.69 & 2.62 \\
Pour point $\left[{ }^{\circ} \mathrm{C}\right]$ & -38 & -42 & -44 & -43 & -41 & -43 \\
VI & 135 & 151 & 150 & 142 & 168 & 178 \\
\hline
\end{tabular}

As shown in figure 1 and table 2, the viscosity of oil decreases with the temperature rising and it is most obvious from $-40^{\circ} \mathrm{C}$ to $0^{\circ} \mathrm{C}$. The lower the Vis-grade of engine oils, the lower is the pour point, the less significant do the low temperature viscosity change. The reference oil has solidified at $-40^{\circ} \mathrm{C}$ while the candidate oils have also been in a state that difficult to flow. And the application of new type VII can improve the viscosity index significantly.

\section{Tests}

Engine Friction Tests. The test engine is used on a domestic mini-automobile, and the technical specifications are shown in table 3. The schematic diagram is shown in fig. 2 , test engine is driven by an outside motor, and torque meter is placed between motor and test engine to measure the engine friction. The couplings are used to make the crankshaft, torque meter and motor be in alignment.

Table 3 Specifications of the Test Engine

\begin{tabular}{cc}
\hline Engine type & 4-cylinder、DOHC、DVVT \\
\hline Displacement & $1.485 \mathrm{~L}$ \\
Compression ratio & $10.2: 1$ \\
Bore $\times$ stroke & $74.7 \mathrm{~mm} \times 84.7 \mathrm{~mm}$ \\
Max power/speed & $78 \mathrm{~kW} / 5800 \mathrm{rpm}$ \\
Max torque/speed & $146.5 \mathrm{~N} . \mathrm{m} /(3600 \sim 4000 \mathrm{rpm})$ \\
\hline Quantity of oil & $4 \mathrm{~L}$ \\
\hline & \\
\hline
\end{tabular}

Fig. 2 Schematic Diagram of Engine Friction Test

Due to the strong surface activity of additives of the energy-conserving engine oils, the metal surfaces can be adsorbed firmly, which means "Carry Effect". Measures that do flushes frequently should be taken before adopting the next test oil. The flushing principle is: Replace oil filter firstly, then flush twice with flush oil and flush once with test oil keeping the engine oil temperature $80 \sim 90{ }^{\circ} \mathrm{C}$.

Test model to measure the engine friction is the common operating conditions in NEDC fuel consumption test cycle and actual life, including three stages with different oil temperatures from $60^{\circ} \mathrm{C}$ to $100^{\circ} \mathrm{C}$ at $20^{\circ} \mathrm{C}$ intervals. Each stage has eight steps with different 
speeds from $800 \mathrm{r} / \mathrm{min}$ to $3200 \mathrm{r} / \mathrm{min}$. When respectively using six kinds of lubricating oils, the engine friction torque at each temperature stage is shown in Fig. 3, Fig. 4 and Fig. 5. The arithmetic average of all operating conditions of the test model can be a solution to evaluate the effect of different oil on friction reduction. The friction reduction rate for five candidate oils relative to the reference oil is shown in Fig. 6.

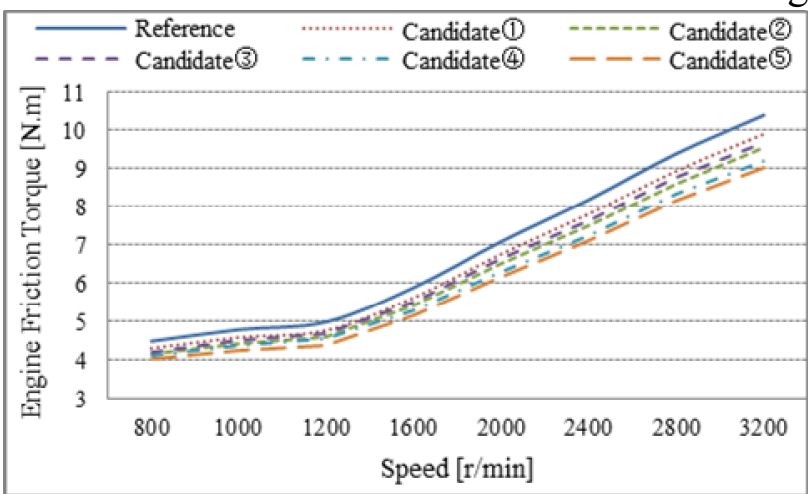

Fig. 3 Engine Friction of Test Oils at $60^{\circ} \mathrm{C}$

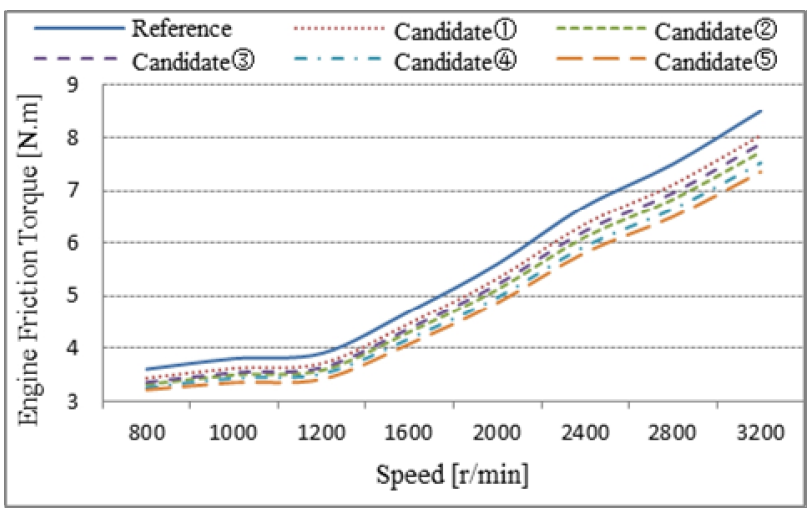

Fig. 5 Engine Friction of Test Oils at $100^{\circ} \mathrm{C}$

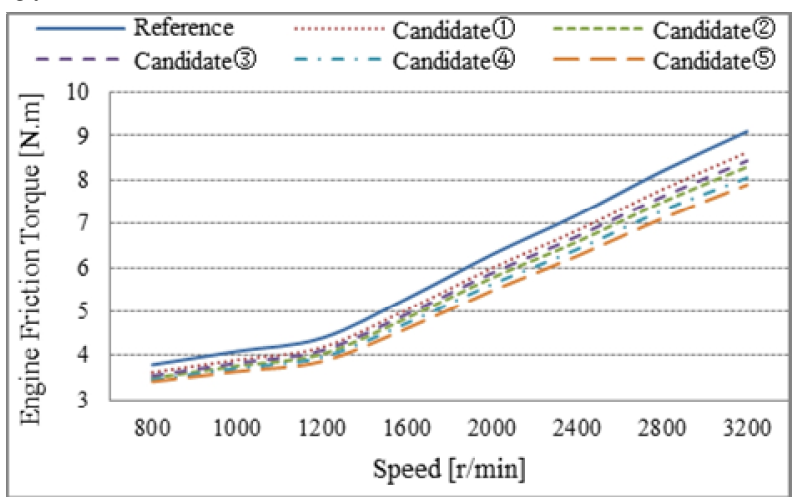

Fig. 4 Engine Friction of Test Oils at $80^{\circ} \mathrm{C}$

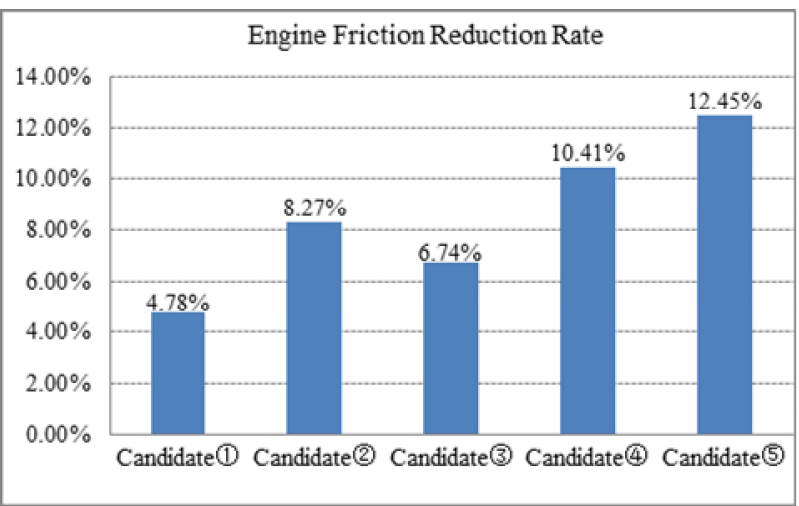

Fig. 6 Engine Friction Reduction Rate

The results indicated: (1)Five kinds energy-conserving engine oils reduced engine friction loss, but showed to different extent, candidate(5) performed best. In other words, reducing the engine oil viscosity, adding high-performance FM or new-type VII could all reduce engine friction loss to some degree, among which, the engine oil Dexos1 5W-20 with 1\% FM and new-type VII worked best with $12.45 \%$ engine friction reduction rate. (2)When Vis-grade was the same, the engine oil of Dexos1 standard had a better result in friction reduction than API SN standard. (3)The friction reduction of energy-efficient engine oil was influenced by the operation conditions. The higher the speed, the more significant the reduction. The higher the temperature, the lower the engine friction. Because the viscosity of engine oil lowers with the temperature rising, which reduces the friction in hydrodynamic lubrication regime. But if the viscosity is too low, the friction in boundary lubrication regime may increase.

Vehicle Fuel Economy Test. According to the national standard "Measurement methods of fuel consumption for passenger cars"(GB/T 12545.5-2008), the tests were completed on the chassis dynamometer under New European Driving Cycle (NEDC) operation in a mini car manufacturer's emissions-laboratory which mainly included AVL 48 "compact chassis-dynamometer, AVL five components emission analyzer, HORIB emission analyzer and some other auxiliary equipments, with strictly controlled test condition like temperature, humidity and pressure. Testing site sketch and NEDC graph are shown in Fig. 7 and Fig. 8 respectively. 


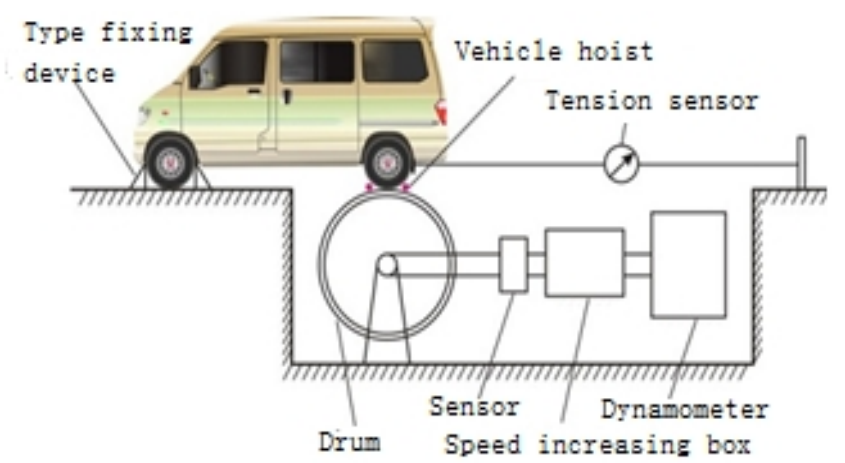

Fig. 7 Diagram of Vehicle Fuel Economy Test

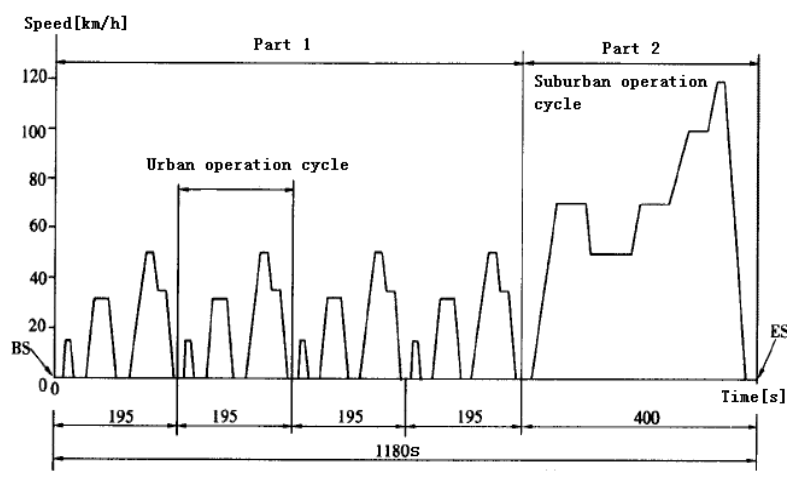

Fig. 8 NEDC Cycle

The fuel consumption is calculated by the following equations in GB/T 19233-2008 Light vehicle fuel consumption test method:

$$
Q=0.1154 \times\left(0.866 Q_{H C}+0.429 Q_{C O}+0.273 Q_{C_{2}}\right) / D
$$

Where $Q=$ fuel consumption $[\mathrm{L} / 100 \mathrm{~km}] ; Q_{H C}=\mathrm{HC}$ emission value $[\mathrm{g} / \mathrm{km}] ; Q_{C O}=\mathrm{CO}$ emission value $[\mathrm{g} / \mathrm{km}] ; Q_{\mathrm{CO}_{2}}=\mathrm{CO}_{2}$ emission value $[\mathrm{g} / \mathrm{km}] ; D=$ density of fuel oil at $15^{\circ} \mathrm{C}[\mathrm{kg} / \mathrm{L}]$.

The impact of engine oil on vehicle fuel economy is complicated and subtle, especially the testing precision. All the factors which may cause test errors, including initial temperature, driver, tire, voltage and equipment calibration, must be controlled strictly to keep consistent.

Test procedure, test times and analysis of statistical data must be strictly controlled as well. Table 4 shows the details of test procedure. The oil tank must be flushed before every test according to the "flushing principle" mentioned above, the reference oil and candidate oils were alternately tested, and every kind oil test was repeated five times, only the test data of last four times were valid. The results of candidate oils must be compared with the results of two neighboring reference oil groups. The results of average vehicle fuel consumption using different engine oil are shown in fig. 9. And the results of Vehicle Fuel Economy Improvement Rate of candidate oil are shown in fig. 10.

Table 4 Test Procedure

\begin{tabular}{ccc}
\hline Step No. & Cycle & Oils \\
\hline 1 & Oil flush & Flush oil $(2 \times)+$ Reference oil $(1 \times)$ \\
2 & NEDC + NEDC $(4 \times)$ & Reference oil \\
3 & Oil flush & Flush oil $(2 \times)+$ Test oil $(1 \times)$ \\
4 & NEDC + NEDC $(4 \times)$ & Test oil \\
5 & Oil flush & Flush oil $(2 \times)+$ Reference oil $(1 \times)$ \\
6 & NEDC + NEDC $(4 x)$ & Reference oil \\
\hline
\end{tabular}

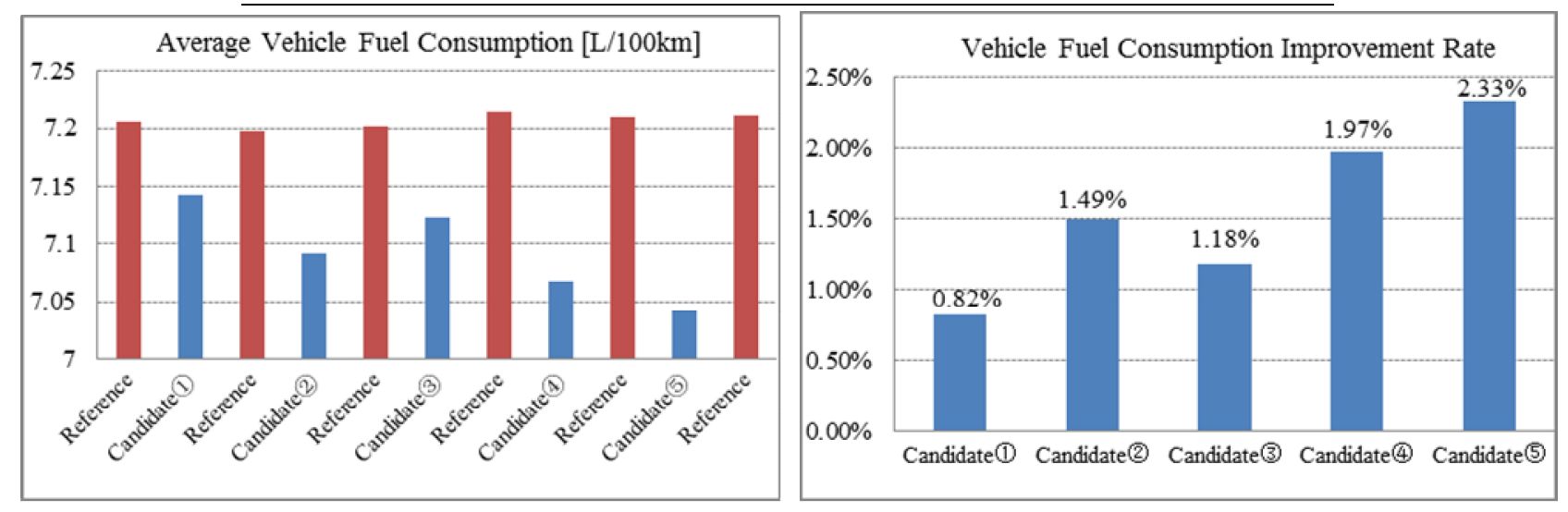

Fig. 9 Average Vehicle Fuel Consumption

Fig. 10 Vehicle Fuel Economy Improvement Rate 
The results showed as follows: (1)The results of six reference oil groups kept small fluctuation, which proved reliable testing precision and stability. (2)Five kinds of energy-conserving engine oil improved vehicle fuel economy to different degree, which means reducing the oil viscosity, adding FM and new-type VII worked to a certain degree, among which, the engine oil Dexos $15 \mathrm{~W}-20$ with 1\% FM and new-type VII worked best with 2.33\% vehicle fuel economy improvement, which was consistent with the result of engine friction loss reduction. (3)The fuel economy of Dexos 1 engine oil was $0.36 \%$ higher than the one of API SN engine oil with the same viscosity grade.

\section{Conclusions}

(1)Several kinds of energy-conserving engine oils with different Standard, Vis-grade, FM, and VII were blended and showed different extent performance in engine friction loss reduction and vehicle fuel economy improvement.

(2)The effect of energy-conserving engine oils Dexos1 5W-20 adding 1\% FM and new-type VII was most significant with $12.45 \%$ friction reduction and $2.33 \%$ vehicle fuel economy improvement.

(3) At the same viscosity grade, the vehicle fuel economy of Dexos 1 engine oil is $0.36 \%$ higher than the one of API SN engine oil.

(4)The vehicle fuel economy is highly correlated with engine friction loss. $5.5 \%$ engine friction loss reduction is approximately equivalent to $1 \%$ vehicle fuel economy improvement.

(5) High Standard, low viscosity and the high-performance special additives of engine oil formulation technology has further potential for fuel economy improvement.

\section{References}

[1] [In Chinese] Linchun Wang, Liping Wang, Guiyun Li, et al. Analysis of Gasoline Engine Oil Fuel Economy's Influence Factors [J], Lubes \& Fuels, 2013,23(2): 8-11.

[2] [In Chinese] Baojun Jia, Ning Han, Kejing Zhang. Automobile Energy-saving Requirements and Development of Lubricant Technology [J], Lubricating and Sealing, 2006(3): 175-180.

[3] Seik Park, Yengun Cho, Kwunsup Sung, et al. The Effect of Viscosity and Friction Modifier on Fuel Economy and the Relationship Between Fuel Economy and Friction, SAE Paper, 2009-01-2662, 2009.

[4] Nobuo Ushioda, Trevor W. Miller, Carrie B. Sims, et al. Effect of Low Viscosity Passenger Car Motor Oils on Fuel Economy Engine Tests, SAE Paper, 2013-01-2606, 2013.

[5] Wim van Dam, Peter Kleijwegt, Marnix Torreman, et al. The Lubricant Contribution to Improved Fuel Economy in Heavy Duty Diesel Engines, SAE Paper, 2009-01-2856, 2009.

[6] Thomas E. Hayden, Charles A. Ropes and Michael G. Rawdon. The Performance of a Gasoline Friction Modifier Fuel Additive, SAE Paper, 2001-01-1961, 2001. 